\title{
As Interfaces do Turismo nas Praias de Jericoacoara e Tatajuba: políticas, conflitos e gestões
}

\section{The Interfaces of Tourism in Jericoacoara and Tatajuba Beaches: policies, conflicts and managements}

\author{
Luzia Neide Coriolano $^{1}$ \\ Eluziane Gonzaga Mendes ${ }^{2}$
}

\begin{abstract}
Resumo
Este artigo analisa a interface do turismo global de Jericoacoara com a construção do turismo comunitário em Tatajuba, no município de Camocim, litoral oeste do Ceará. Esta comunidade complementa o turismo de Jericoacoara, tornando-se objeto de interesse da especulação imobiliária e das empresas do turismo. Este fato gerou conflitos, que se apresentaram pela desarticulação entre os moradores e divisão interna, no entanto, despertou na comunidade a resistência ao turismo de grandes empreendimentos, com a descoberta de possibilidades, sendo o turismo comunitário uma das perspectivas.
\end{abstract}

Palavras-Chave: turismo global; conflitos; turismo comunitário.

\section{Abstract}

This paper analyses the interface between the global tourism in Jericoacoara and the development of the local tourism in Tatajuba Beach, in the county of Camocim, on the west coast of Ceará. As part of the touristic complex of Jericoacoara, this community has attracted real estate speculation, and special interest from the tourism agencies. This has caused conflicts among its residents and split-ups within the community. However, these conflicts also raised the residents awareness about the possibility of developing its local tourism as opposed to the global tourism of large agencies.

Keywords: global tourism; conflicts; local tourism.

\section{Introdução}

Este artigo apresenta uma análise da interface do turismo global de Jericoacoara com o turismo comunitário de Tatajuba. Esta é uma das praias do município de Camocim, no litoral

\footnotetext{
${ }^{1}$ Profa. Dra. de Geografia e Turismo do Mestrado Acadêmico em Geografia-UECE e Coordenadora do Grupo de Estudos Turismo e Território - NETTUR. E-mail: luzianeidecoriolano@gmail.com

${ }^{2}$ Mestre em Geografia pela Universidade Estadual do Ceará - UECE, Técnica em Turismo e pesquisadora do Laboratório de Estudos do Território e do Turismo - NETTUR. E-mail: eluziane@gmail.com
} 
oeste do Ceará, que integra o turismo de Jericoacoara. Entende-se por turismo global o modelo estabelecido pela "indústria" do turismo pautado no consumo dos serviços, paisagens e culturas, objetivando a acumulação capitalista, pelo fluxo intenso de turistas.

No Ceará, a praia de Jericoacoara é um núcleo turístico consolidado e internacionalmente conhecido. É considerada uma das mais belas praias cearenses e um dos atrativos mais cobiçados e valorizados no litoral do Nordeste do Brasil.

O fluxo intenso de turistas nacionais e estrangeiros de Jericoacoara para a praia de Tatajuba fez aumentar a cobiça de empresários pelas áreas do litoral de Camocim, que ainda não estavam inseridas no circuito do turismo, tornando esse município objeto de interesse da especulação imobiliária, das empresas e das Políticas Públicas de Turismo. Este espaço de reserva entra no circuito do consumo. Empresários compram ou dizem ser proprietários de grandes extensões das terras locais, mesmo em áreas pertencentes à União, por serem terrenos de marinha, como exemplo, a praia habitada de Tatajuba. A revalorização do litoral oeste do Ceará dá-se, ainda, pelo Programa de Regionalização do Turismo, que indicou esta região para integrar o roteiro - Ceará-Piauí-Maranhão (CE-PI-MA). O litoral oeste serve de exemplo de turismo regionalizado. Esta regionalização integra os roteiros turísticos do litoral oeste cearense - com o delta do Parnaíba - e os lençóis maranhenses, cuja intenção é viabilizar demandas de consumo desta moderna mercadoria - o turismo.

As políticas de regionalização promovem uma nova produção espacial e novos usos, que contribuem para ensejar conflitos pela posse da terra e por espaços para a implementação do turismo. Tatajuba apresenta-se como uma das comunidades que enfrenta destemidamente a defesa de suas terras. Essa agressiva reordenação territorial e a cooptação de lugares para a produção de espaços turísticos situou o litoral cearense no menu do mercado mundial, ocasionando impactos socioambientais. Novas áreas configuram-se, apesar de uma série de embates pela apropriação e uso da terra.

A comunidade de Tatajuba, em Camocim, vivencia conflito fundiário entre grileiros, especuladores e empresa imobiliária. Estes buscam apropriar-se de terras para seus empreendimentos e a comunidade luta para defender suas posses. O conflito instigou parte dos moradores a resistir ao turismo de resorts e aos grandes empreendimentos imobiliários. As reações são esboçadas mediante crítica ao turismo global, levando ao fortalecimento da organização dos residentes em associações para luta, defesa de suas terras e construção de um 
outro turismo de base local, com pequenas pousadas, privilegiando os costumes tradicionais, denominado pelos residentes de turismo comunitário.

A complexidade que se encontra na dinâmica do turismo e sua interface entre as praias de Jericoacoara e Tatajuba incitou o desenvolvimento desta pesquisa no mestrado que se realizou entre 2004 a 2006. Diversas viagens foram realizadas, e em campo, a investigação etnográfica e abordagem qualitativa, conduziram as entrevistas, a observação participante, a apreensão da história oral e a história de vida dos moradores. Para Haguette (1987, p.55), "os métodos qualitativos enfatizam as especificidades de um fenômeno em termos de suas origens e de sua razão de ser". Compreende-se que os dados precisam de interpretação, para tanto, são subsidiados pelas teorias críticas das ciências sociais. Neste artigo, trechos dos relatos exemplificam e revelam como se dá a configuração do turismo global nas comunidades litorâneas do Ceará, e em contrapartida, a construção de novas propostas para o turismo pela gestão comunitária.

\section{O Lugar Turístico: a comunidade de Tatajuba (CE)}

A comunidade de pescadores Tatajuba localiza-se no Distrito de Guriú, no Município de Camocim. O caminho mais rápido para o lugar é pela praia de Jericoacoara. Leva-se aproximadamente seis horas de viagem, saindo de Fortaleza. Por essa trilha tem-se a oportunidade de observar as paisagens das praias cearenses, no litoral oeste. Após passar por Jericoacoara, percorre-se a distância de $12 \mathrm{~km}$ até a vila do Guriú, atravessando-se de balsa (movida a força humana), o lago da Forquilha - conhecido como lago do Urubu, percorrendose mais $18 \mathrm{~km}$ pela praia e após esperar a maré baixar, atravessa-se a gamboa para chegar ao centro da vila de Tatajuba. O lugar é possuidor de um conjunto natural constituído por mar, praia, complexo de dunas fixas, semifixas e móveis, lagoas costeiras, gamboas, tabuleiros, mangue, entre outros, a natureza desse lugar revela-se com exuberância.

Chegar a Tatajuba ${ }^{3}$ é uma grande aventura, não é tarefa simples. No século XXI, quando todas as facilidades da tecnologia colaboram para que se chegue a qualquer lugar, estas

\footnotetext{
${ }^{3}$ No ano de 1930, a comunidade decidiu mudar o nome do vilarejo de Cabaceiras para TATAJUBA, em razão da abundância dessa árvore na praia. Girão (1971, p.34), pesquisador da História cearense, descreve as características dessa espécie vegetal, "a tatajuba, ou pau de tinta, é madeira de cor amarela, da família das urticáceas (Chorophora tinctoria Gand)”.
} 
dificuldades são consideradas atrativos turísticos. Os caminhos que levam à comunidade são caracterizados pela aventura que deve ser conquistada. Foi no início do século XX, que pescadores desbravaram o caminho das dunas para encontrar em Tatajuba um lugar perfeito para a produção da pesca e, especialmente, da lagosta. Os moradores asseveram que a pesca foi uma das principais motivações da formação da vila. Os relatos coletados informam que as primeiras famílias a chegarem nesse lugar vieram de núcleos de povoamento dos arredores, atraídos pela pesca em abundância, o que estimulou a formação da comunidade. No mapa a seguir (Mapa 1), observa-se o litoral do Ceará e a localização da área de estudo. Camocim é o penúltimo município do litoral oeste, quase fronteira com o Piauí. Neste município, localizase a comunidade de Tatajuba, que dista $18 \mathrm{~km}$ da sede e está cerca de $340 \mathrm{~km}$ de distância de Fortaleza, capital do Estado, indo pela praia. Destaca-se ainda a localização da praia de Jericoacoara, pela proximidade e interfaces com Tatajuba.

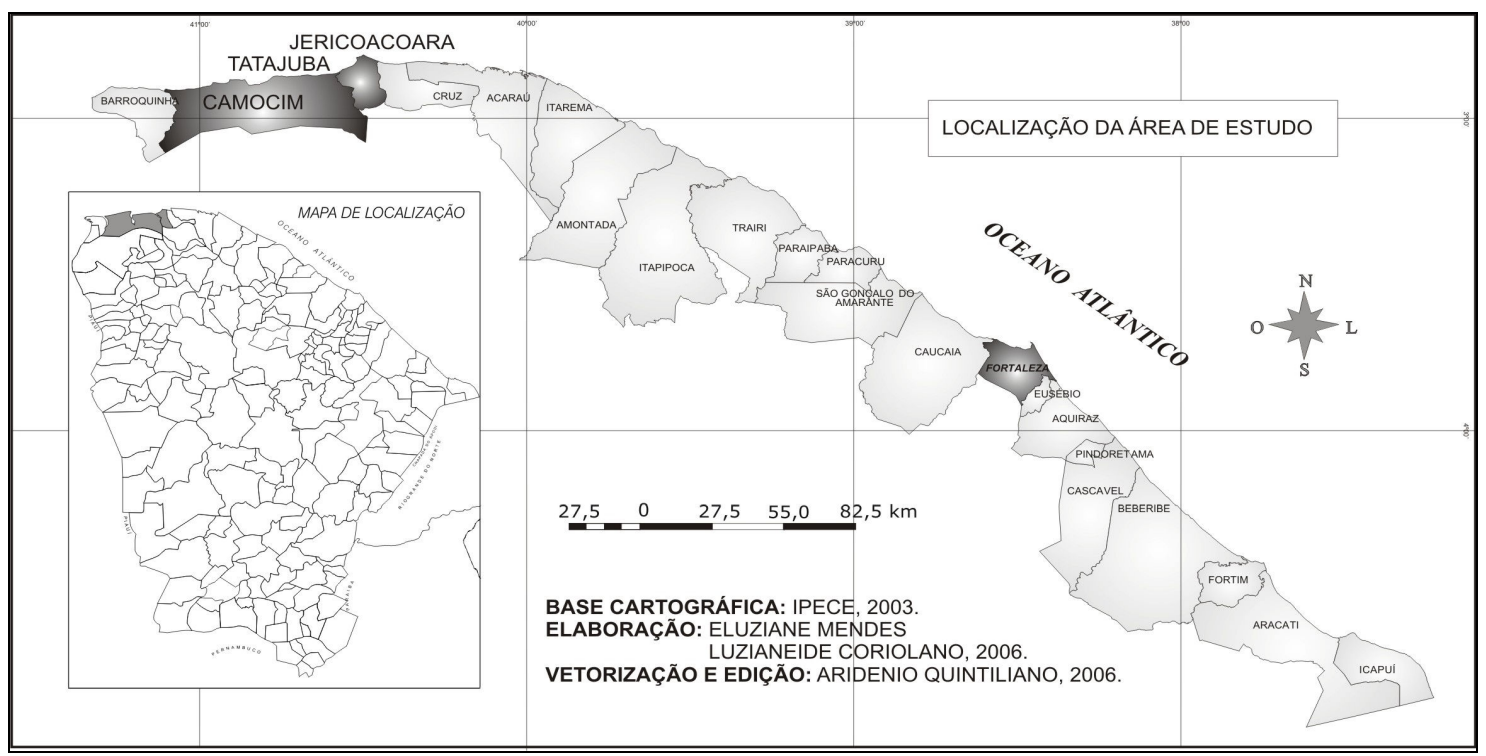

Mapa 1- Litoral do Ceará e a localização da área de estudo

A história oral revelou que a comunidade tem por marco inicial o ano de 1902, quando a ocupação deu origem a dois núcleos: Cabaceiras de Cima e Cabaceiras de Baixo. A primeira assim denominada por localizar-se à margem direita de uma gamboa, com topografia mais elevada; e a segunda, no lado esquerdo, com topografia mais baixa. A toponímia surgiu da 
existência de muitas plantas de cabaça (crescentia cujete) nas proximidades da praia, registrada pelas primeiras famílias.

Na década de 1978, os moradores de Tatajuba tiveram que se deslocar em virtude do movimento das dunas que migravam em direção às casas, do lado leste para oeste, soterrandoas, até mesmo a Igreja, cujo padroeiro é São Francisco foi soterrada. A gamboa ${ }^{4}$ que existe no lugar teve seu curso deslocado e, resultou na divisão da vila ${ }^{5}$ em quatro núcleos: o de Tatajuba (também chamada de Nova Tatajuba e núcleo central), Vila São Francisco, Vila Nova e Vila da Baixa da Tatajuba, favorecendo a passagem das dunas, livrando as casas de futuros soterramentos. Na figura 1, a seguir, pode-se observar a duna barcana, que através de sua migração, foi responsável pelo soterramento da antiga vila de Tatajuba. As dunas barcanas são consideradas pela comunidade como encantadas. Muitas lendas são originadas da existência dessa duna e fazem parte do imaginário popular.

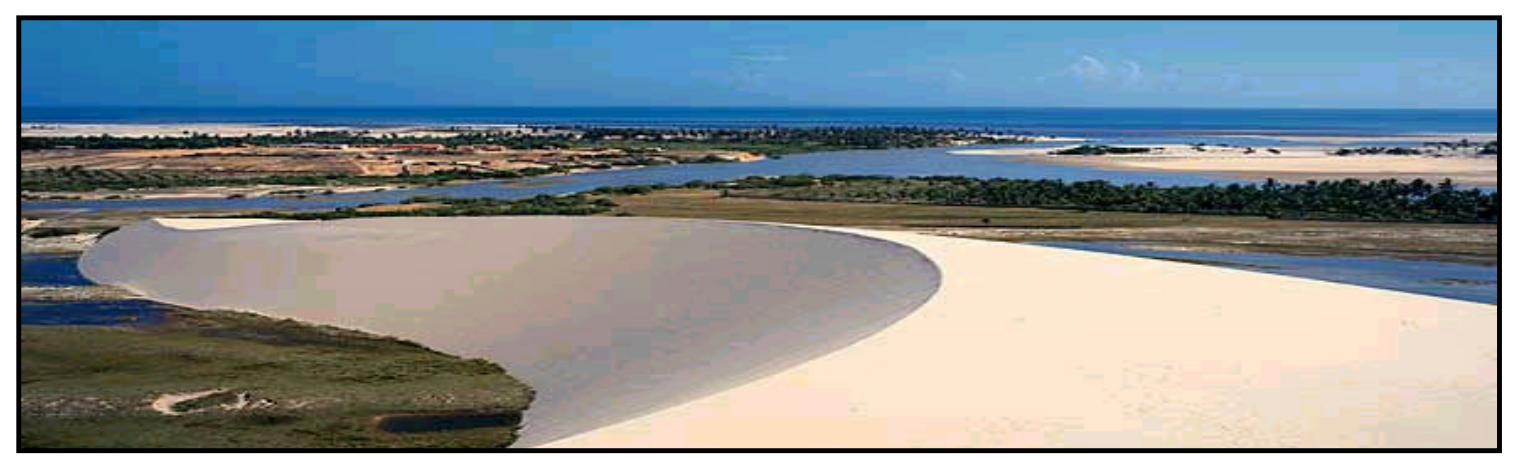

Figura 1- Vista da barcana em Tatajuba, denominada de duna "encantada" Fonte: Disponível em: <http:www.tatajuba.com.br/site/cfm/index_interna.cfm>. Acesso em: 20/10/2004.

\footnotetext{
4 A gamboa é a influência das águas do mar adentrando o continente. Mistura-se com águas de origem continental, formando um ambiente fluviomarinho, resultando no aparecimento do ecossistema manguezal.

${ }^{5}$ Pelas características apresentadas pelo aglomerado que constitui as vilas de Tatajuba, caracteriza-se pelo IBGE (2000, p.17) como um povoado, isto é, "aglomerado rural isolado que corresponde a aglomerados sem caráter privado ou empresarial, ou seja, não vinculados a um único proprietário do solo, cujos moradores exercem atividades econômicas, quer primárias, terciárias ou mesmo, secundárias, no próprio aglomerado ou fora dele. O aglomerado isolado rural isolado do tipo povoado é caracterizado pela existência de serviços para atender aos moradores do próprio aglomerado ou de áreas rurais próximas".
} 
A vila central de Tatajuba divide-se em dois núcleos, o que fica de frente para o mar e o outro mais para o interior. Juntos, os núcleos formam aproximadamente 80 casas. Essa vila é considerada o centro do povoado, onde estão concentrados os principais serviços e equipamentos urbanos, como: posto de saúde; Escola de Ensino Fundamental e Médio, além de cursos para Educação de Jovens e Adultos, a igreja e a Associação Comunitária dos Moradores de Tatajuba. A praça foi construída em 1994, com gerador para televisão comunitária; comércios, barracas na praia; mercearias; bares; pousadas e casas com quartos de aluguel para turistas, ou seja, é um vilarejo. A comunicação é realizada por meio do telefone público, instalado em 1998, alguns telefones celulares e pelas estações de rádio de Camocim. As outras vilas são mais rurais, concentram as casas e os moradores vivem principalmente da agricultura (feijão, macaxeira, batata doce, mandioca, entre outros), coleta e criação de animais de pequeno porte e das casas de farinha.

Em 2005, habitavam nas quatro vilas: Tatajuba, Vila Nova, Baixa da Tatajuba e Vila São Francisco, cerca de 190 famílias, conforme dados fornecidos pelo agente de saúde da comunidade, compondo uma população de aproximadamente mil habitantes, entre adultos, jovens e crianças, com maioria de jovens. A maioria orienta-se pelo ritmo das marés, tanto para produção da pesca como para conseguir realizar o deslocamento de uma vila para outra, pois necessitam atravessar as gamboas. Em Tatajuba os moradores sobrevivem, principalmente, da pesca de peixes, da lagosta, coleta de mariscos, comércio e trabalhos públicos na escola e no posto de saúde.

Os riscos no mar, no extremo oeste do Ceará, sugeriram a utilização das canoas, ao invés das jangadas. Um pescador do lugar revelou (2005) que: "a canoa faz parte da tradição. Antigamente faziam a canoa de facão. Com o tempo aumentaram o tamanho da canoa, e isso diminuiu a quantidade de acidentes". No litoral leste, utilizam a jangada, que é mais plana e tem menores dimensões, diferente das características das canoas, como as utilizadas pelos pescadores de Tatajuba. Os pescadores revelaram ainda, que temem a "extinção" da pesca tradicional, pois alegam não receber investimentos e apoios que contribuam para o desenvolvimento e a continuidade desse tipo de pesca, conservadora do ambiente marítimo. Um dos pescadores, filho de pescador, externou em seu depoimento um apelo a favor da pesca, pois atualmente, o Estado direciona recursos ao capital globalizado que se configura com a expansão do turismo, contribuindo para revalorização das terras litorâneas, resultando 
nos conflitos pela posse da terra, assim como ocorre na comunidade. Nesse sentido, o Poema Tatajuba, criado por um dos moradores $(2001)^{6}$, revela a beleza natural do lugar e denunciam os conflitos provocados pela empresa que especula este litoral:

É um lugar tão bonito com paisagem e beleza não construído pelo homem, mas pela mãe natureza. Obrigado mãe querida the ofereço a minha vida por ter feito essa grandeza.

Quem morar neste lugar bom resultado terá, mas cuide com bem cuidado tem gente que quer tomar. E quem tiver seu quintal cuidar não é nada mal só não pode vacilar.

Tudo que estou falando vocês podem acreditar, eu sou contra essa empresa que quer nos atormentar. Agora caros amigos vocês sabem o resultado nem o pequeno cercado vamos poder aumentar por causa dessa empresa que se encantou com a beleza que existe neste lugar.

Muitas comunidades pesqueiras passam por este mesmo problema, isto é, a luta pela posse de terras e sua permanência no litoral. $\mathrm{O}$ veraneio e a atividade turística entraram no cenário das comunidades litorâneas do Ceará, a partir da década de 1980. Esta atividade estimulou a grilagem, especulação e revalorização das terras do litoral, tanto por elementos exógenos quanto endógenos às comunidades.

Tatajuba é uma comunidade tradicional de pescadores, é um lugar, e assim "cada lugar é, à sua maneira, o mundo", como enfatiza Santos (2002, p.314). Nesse sentido, deve-se buscar a compreensão dos elementos que singularizam os lugares, e ao mesmo tempo, os elementos que o aproximam do mundo, encontrando os seus significados. Maldonado (1993, p.34), em estudos sobre comunidades pesqueiras, ressalta que a noção de lugar é fundamental na análise de comunidades e assinala que "o lugar, a existência local dos fenômenos tanto no espaço fisico como no espaço social é que lhes confere essência, significado e transcendência. É localmente que nos situamos e é localmente que as coisas acontecem". Acrescente-se que, localmente, se percebe no empírico as contradições do mundo, e, ao dizer de Santos (2005, p.161), "hoje, certamente mais importante que a consciência do lugar é a consciência do mundo, obtida através do lugar".

\footnotetext{
6 Poema TATAJUBA. 2001. Autor: Morador de Tatajuba. Disponível em: $<$ http:www.geocities.com/novatatajuba $>$. Acesso em: 6 de abril de 2005.
} 
A análise sobre a comunidade busca apreender a interface entre o turismo global de Jericoacoara, com o processo de uso e apropriação de terras de Tatajuba, que se mantiveram conservadas pela comunidade tradicional de pescadores e, nas últimas décadas, vêm sendo gradativamente revalorizadas para o desenvolvimento do turismo, cujo processo produz permanentes embates. Acirra-se pela instalação de novas atividades privadas e públicas, que tentam se implantar nesse espaço costeiro, respaldadas pelas políticas do Estado, agindo como reestruturadoras dos lugares e territórios.

Apesar dos conflitos pelo uso e apropriação do espaço litorâneo, na comunidade de Tatajuba, ressaltem-se a calma e a vida pacata dos moradores, a exuberância da paisagem, formada por natureza conservada, enquadrando-se no rol dos chamados lugares paradisíacos para o turismo. As paisagens de Tatajuba são utilizadas como fatores de atração de turistas para este litoral, vendidas no pacote turístico de Jericoacoara.

\section{Tatajuba: passeios e rotas do turismo global}

"Eles passam" - essa é a expressão do morador de Tatajuba, reportando-se aos turistas vindos de Jericoacoara, comunidade turística que se localiza no Município de Jijoca de Jericoacoara, limitando-se com o Município de Camocim, onde se localiza Tatajuba, portanto, comunidades vizinhas. Assim, os residentes de Tatajuba e de Jijoca reclamam por que os seus lugares são apenas passagens de turistas, e não um pólo turístico.

Passa muito turista por aqui. Tatajuba faz parte de uma rota de Camocim-Jeri e de Jeri até Camocim. E também durante o dia os turistas vão para a Lagoa da Torta que é atrativo turístico. Quando eles compram os pacotes em Jeri, já inclui o passeio para Tatajuba. Eles passam! (Depoimento de um pescador, nativo de Tatajuba, PESQUISA DE CAMPO, 2006).

Jericoacoara era uma vila de pescadores que se assemelhava à de Tatajuba, conforme os depoimentos dos residentes do lugar, em pesquisa realizada em janeiro de 2006 . Dentre as declarações que fizeram menção a Tatajuba e ao início da construção de pousadas no local, destacam-se algumas (NETTUR, 2006):

Jeri era Tatajuba antigamente. 
Antigamente, Jericoacoara era bom também. Existia fartura da pescaria e plantação. Hoje com o turismo ninguém planta mais. Tudo tem que ser comprado.

Tatajuba, a comunidade é mais unida, diferente de Jericoacoara onde a comunidade não trabalha em grupo.

Tatajuba é bom, mas já se tem iniciado a construção de pousada no local, mas ainda não se tem a mesma movimentação que em Jericoacoara.

Com os fluxos de turistas consolidados no roteiro Jeri -Tatajuba, os moradores da comunidade demonstram preocupação em seus depoimentos. Na realidade, esta é a preocupação dos moradores que não estão incluídos na cadeia produtiva do turismo, pois os proprietários de barracas, bares e restaurantes na lagoa da Torta, estão satisfeitos. Revela-se no depoimento do morador a satisfação dos barraqueiros, a adaptação pelo modelo de turismo e a defesa pela entrada de empresas na comunidade. Os moradores mais "conscientes" compreendem que esse turismo não é viável a uma grande maioria e propõem um turismo alternativo, voltado às demandas de menor poder de consumo e, sobretudo, para aqueles que buscam conhecer as culturas das comunidades tradicionais:

Os turistas muitas vezes compram uma água de coco, comem um peixe lá na lagoa. Lá tem barraca é um lugar muito bonito. Quem vende lá são daqui. As pessoas que estão lá vendendo na lagoa estão felizes e defendem as empresas, porque acham que é dessa forma é que o desenvolvimento, é do jeito que está aí. Eles estão vivendo do turista. Se a senhora for comer um peixe lá, a senhora volta é tudo muito caro. Porque a maioria dos turistas é tudo gringo. Eles acham que todo mundo que vai pra lá é estrangeiro. Eles exploram o turista. Para eles é um grande investimento. Para quem pensa num turismo diferente aquilo é uma exploração (Pescador, 29 anos, PESQUISA DE CAMPO, 2006).

Em “Jeri”, nome reduzido do lugar, acatado pelos turistas, ofertam-se passeios à lagoa Azul, ao mangue Seco e também à lagoa da Torta em Tatajuba. A partir dessa rota, alguns turistas e visitantes passaram a conhecer Tatajuba, dizendo-se encantados e, alguns, compraram lotes e instalaram suas próprias pousadas. Dentre os atrativos, os passeios de buggies, as lagoas, o forró na praia, Tatajuba e a lagoa da Torta são os atrativos mais freqüentados. Na coleta de depoimentos dos residentes em Jericoacoara, comprovou-se que Tatajuba é vendida como um dos seus principais passeios turísticos, depois da "pedra furada", estrutura rochosa, ícone da praia de Jeri. Nas fotografias 2 e 3, pode-se observar a lagoa da Torta e os equipamentos de lazer instalados para atrair os visitantes. 


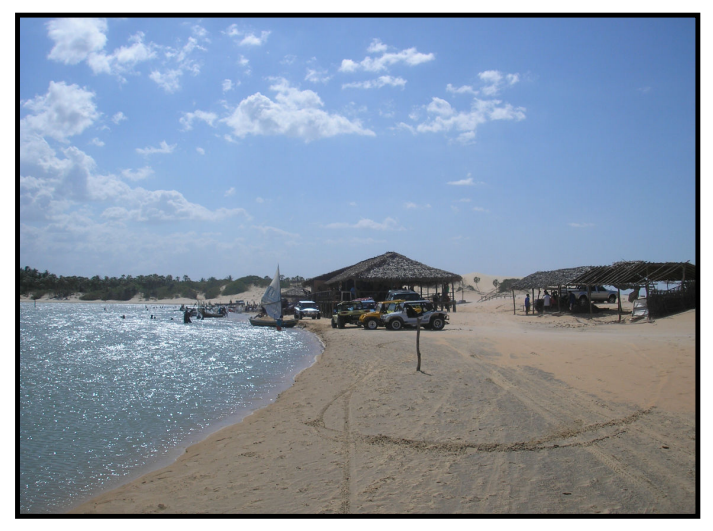

Figura 2 - Lagoa da Torta - Tatajuba

Fonte: CORIOLANO, 2006

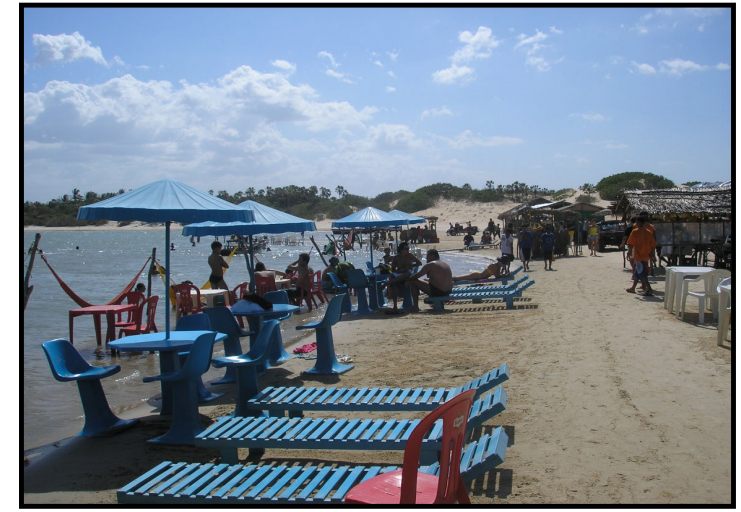

Figura 3 - Equipamentos de lazer na lagoa da Torta

Fonte: MENDES, 2006

A declaração do morador de Tatajuba revela que, na lagoa da Torta, o turismo segue o mesmo ritmo de Jericoacoara, sendo o aumento dos preços e do custo de vida a maior reclamação dos residentes. Vários depoimentos constataram as modificações ocorridas na antiga vila de Jeri e suas mudanças negativas. Um deles falou assim: "a comunidade piorou porque o sossego diminuiu”, “sem o turismo era paz”. Expressam os processos de segregação socioespacial na vila, ao dizer que "o nativo não pode construir, mas o turista pode”, confirmam, dizendo que "estamos perdendo o lugar para os estrangeiros" (Depoimentos dos moradores de Jericoacoara, NETTUR, 2006).

Dentre as modificações ocorridas nessa praia, estão também os impactos ambientais que se intensificam no período de alta estação ou de festividades, com o exorbitante aumento do fluxo de pessoas, usufruindo e utilizando o mesmo espaço. As fossas negras, lençol freático contaminado, lixo, fluxo intenso de automóveis e a construção irregular são apontados como os piores problemas causados na natureza da praia de Jericoacoara. Ressalta-se que as construções irregulares estão contribuindo para a mudança de direção na migração das dunas, que se direcionam para soterrar a vila. 
Apesar dos depoimentos revelarem grandes mudanças sociais e ambientais na vila, outros rebatem, ao afirmarem que, com o turismo tudo melhorou; que a atividade turística trouxe benefícios para a comunidade, sobretudo de infra-estruturas e trabalho. Constatam esse fator ao compararem Tatajuba com Jericoacoara, pois, conforme a pesquisa realizada, cerca de $47 \%$ dos entrevistados, entre turistas e residentes, afirmaram conhecer o lugar, principalmente pelos passeios, respaldando as comparações.

Os moradores de Tatajuba possuem modos próprios de ver e pensar o turismo desenvolvido nesse lugar. O depoimento da moradora de revela o medo que sente da comunidade se transformar num lugar turístico, nos moldes de Jeri:

Jericoacoara eu conheço assim, que tem muitas drogas, tem vários turistas diferentes uns praticam coisas boas, uns coisas ruins. Tem muita droga e isso a gente não quer pra cá. A gente quer que aqui fique sempre assim tranqüilo. Lá os nativos venderam e os que têm terra não têm direito a mais nada, que ali tudo é de novos donos. Aqui a gente não quer isso, a gente quer que os turistas que cheguem aqui seja bom, que beneficie os que moram aqui. Vamos trabalhar juntos. Não que venha o povo de fora, ficam suas pousadas boas, ganhe bom dinheiro e os nativos nada. Isso é que a gente não quer (Moradora de Tatajuba, 30 anos, PESQUISA DE CAMPO, 2004).

Além das interferências provenientes de Jericoacoara, outro fato temido pela comunidade de Tatajuba é que seu espaço se torne um lugar do turismo de grandes empreendimentos, com a instalação de empresa imobiliária que tenta implantar o "Condado Ecológico de Camocim", um complexo para turismo e eventos, em área que compreende 5.275,450 hectares, denominada de Costa da Tatajuba.

Os empresários alegam que a área corresponde a duas fazendas - a Vitória Régia e a fazenda Tatajuba. Em informações coletadas na Secretaria de Turismo do Ceará ${ }^{7}$, soube-se que esse empresário realiza um trabalho de atração de investidores para as terras das quais se diz proprietário, sobretudo daqueles que desejam se agregar ao projeto Condado Ecológico de Camocim (FRANÇA, 2006). A empresa apresenta os elementos de marketing do negócio, incluindo as paisagens e festividades do lugar como parte de seus atrativos. Assinalam, ali,

\footnotetext{
${ }^{7}$ Informações fornecidas pela Secretaria de Turismo do Estado do Ceará, Coord. de Atração de Investimentos e Fomento, em entrevista concedida em março de 2006.
} 
que o empreendimento será "um novo conceito de desenvolvimento econômico-social sustentável, em terras de grande beleza natural”. O Hotel Aventuras foi o primeiro equipamento instalado na área, que, de acordo com o depoimento da moradora de Tatajuba (PESQUISA DE CAMPO, 2006), se localiza “na Baixa Grande, no Guriú, onde a empresa tem sua sede e um hotel”. Os empresários garantem que vão surpreender o turista, e para alcançar essa meta, asseguram que protegerão a biodiversidade, iriam criar programas de inclusão social para os moradores locais e tornarão a área atrativa a investimentos. Isto é, associados ao Estado, por meio das políticas de investimentos, reestruturarão o território para o comércio, conforme as estratégias demonstradas. Além destas, os moradores de Tatajuba revelam que os empresários chegaram na comunidade oferecendo diversos benefícios:

Quando a empresa chegou, eles começaram a formar estratégias de trabalho para poder conquistar o pessoal, o morador. No início eles trouxeram curso de artesanato e quiseram formar uma cooperativa. Formaram um coral, que até hoje, é o que existe e mantêm eles ainda segurando as pessoas e outras coisas. Tem um professor de Camocim que vem todos os sábados dar aulas de canto e de instrumentos. É o que eles estão segurando (Liderança da ACOMOTA, 30 anos, PESQUISA DE CAMPO, 2006).

Muitas são as promessas feitas aos moradores da comunidade, sobretudo a criação de empregos e "inclusão social". O representante ${ }^{8}$ da Comissão dos Direitos Humanos da OAB e do Escritório Frei Tito de Alencar, na audiência pública de 2001, realizada em Camocim, com representantes da comunidade, da empresa e da sociedade civil, ratificou, a essência das empresas:

Empresa visa lucro. É fantasia achar que uma empresa vem pra cá para distribuir riqueza com a comunidade. Todo empreendimento traz também "benefícios sociais", dá empregos etc. Mas fundamentalmente, empresa quer lucro (COMISSÃO ..., 2001).

Os moradores de Tatajuba são pessoas que vivem das atividades tradicionais como a pesca, agricultura, coleta, serviços e pequenos comércios, e temem que isso desapareça. Nesse

\footnotetext{
${ }^{8}$ Advogado Deodato Ramalho, representante da Comissão dos Direitos Humanos da OAB e o do Escritório Frei Tito de Alencar.
} 
sentido, alguns moradores acreditam que um empreendimento de grande porte desestruturaria as atividades econômicas locais, sem oferecer desenvolvimento para o lugar, como é prometido. Constata-se tal preocupação, nas palavras do morador:

O empreendimento pra nós aqui não é bom não. Porque, como é que nós ía trabalhar com um empreendimento do turismo, se nós não sabemos trabalhar com o turismo. Eles é que vão tomar de conta de tudo. Nós não vamos ser nem empregados dele, com certeza (Pescador de Tatajuba, 65 anos, PESQUISA DE CAMPO, 2004).

O turismo transforma os lugares em objetos mercadológicos, valorizando o espaço em função do valor de troca e do consumo. O espaço vira mercadoria para o turismo, mas, para continuar no mercado, as políticas criadas apóiam as empresas, desconsiderando a dimensão social, assim como ratifica Beni (2005), ao dizer que "são elas as que mais se beneficiam das políticas públicas de promoção, as que têm acesso ao financiamento e encontram condições favoráveis para incorporar novas tecnologias".

O conflito pela terra com os grileiros, especuladores e empresas imobiliárias incita ações de resistência ao turismo globalizado e seus grandes empreendimentos. O mapeamento dos investimentos turísticos na área de Camocim explica a revalorização da terra litorânea, para o mercado turístico internacional. Evidencia a constante tensão em defesa da posse da terra, fazendo surgir uma nova proposta de turismo - o comunitário. Esta forma leva as comunidades a buscar sua inserção na cadeia produtiva do turismo. A versão comunitária do Turismo em Tatajuba é um projeto em construção que "caminha" lentamente. O turismo denominado "global", no entanto, acelera sua implantação, através dos equipamentos hoteleiros, como poderá ser constado no próximo segmento.

\section{O Turismo Comunitário em Tatajuba: nova proposta}

O Turismo Comunitário é desenvolvido utilizando-se dos recursos naturais e culturais existentes nos lugares. Diferencia-se do turismo de massa, global, pois este se realiza pela implantação de grande infra-estrutura, além do marketing intenso para tornar o lugar conhecido (MENDES; CORIOLANO, 2003). Já essa nova política de turismo, também chamada de Turismo Socialmente Responsável, tenta priorizar a conservação do meio 
ambiente e das culturas tradicionais. É a alternativa encontrada pelas comunidades que buscam desenvolver o turismo, criando oportunidades de trabalho, complementando a renda dos moradores. As ações são tentativas de constituir uma política comunitária e social, cujo objetivo é a permanência e sobrevivência no espaço litorâneo.

As políticas de turismo comunitário são apoiadas pelas iniciativas das organizações nãogovernamentais que contribuem na implantação dos pequenos negócios, além de realizar o marketing turístico dos lugares, atraindo os turistas às comunidades, com a oferta de produtos simples, culinária, artes e cultura. Nesse sentido, acreditam que se torna mais fácil, criar laços de comunicação e respeito mútuo entre turista e morador, sendo as relações mais solidárias e pessoais, em oposição do turismo "global", em que as relações são marcadas pela impessoalidade e distância.

Na dimensão comunitária, a atividade turística é pensada, ainda, como forma de reação, mas, ao mesmo tempo, é uma inserção na economia. É a reprodução em dimensões microescalares, pois não foge do modelo capitalista de geração de renda, mas se apresenta como uma nova proposta, por ser uma política “de baixo para cima”, gestada pela comunidade; uma política comunitária que busca beneficiar a base e não às grandes empresas pertencentes ao circuito mundial da economia. Caracteriza-se como uma reação ao turismo dito global, que se realiza sem a participação dos residentes, alguns deles, não aceitam "calados" a implantação das grandes empresas turísticas, ao contrário, buscam criar possibilidades de trabalho para os moradores, por intermédio de projetos endógenos que contribuam para a sobrevivência.

A vila de pescadores da Prainha do Canto Verde, no litoral leste, em Beberibe, é um dos exemplos de política comunitária no Ceará, onde os agentes são os moradores da comunidade (MENDES; CORIOLANO, 2003). A vila tornou-se referência para outros lugares, como a comunidade de Tatajuba, que busca desenvolver o local pautado na conservação da natureza e respeito às culturas tradicionais. A política dos desprovidos de capital apresenta-se por suas dimensões comunitárias. Na sociedade da mercadoria, os produtos são constantemente criados e recriados, no mercado formal e informal. Em relação ao turismo comunitário, certamente, não acompanham os mesmos padrões e selos de luxuosidade. O turismo apresenta-se como alternativa de geração de renda e complemento às atividades extrativistas tradicionais (pesca, agricultura e a coleta). Apontado como alternativa de renda, nos documentos elaborados sobre 
Tatajuba, isto é, laudo técnico do IBAMA (2001), Diagnóstico Socioparticipativo (TERRAMAR; UFC, 2002) e outros elaborados pelo governo (PDTIS, 2003).

A infra-estrutura turística é simples, no entanto, no período da realização deste estudo, que compreendeu os anos de 2004 a 2006, constatou-se um crescimento dos meios de hospedagem, assim como da construção de casas dos moradores. A hospedagem é feita nas pousadas e quartos de aluguel, distribuídos na vila de Tatajuba. Os quartos domiciliares são estruturas modestas, mas acolhedoras. Oferecem lanches, almoços e jantares, sendo que o peixe frito, a moqueca de arraia e os crustáceos, como o camarão ao alho e olho, são os pratos regionais.

Enquanto a problemática da posse da terra não é resolvida, alguns moradores buscam opções para sobreviver no lugar, com pequenos negócios turísticos. As barracas na praia e na lagoa da Torta são elementos da infra-estrutura turística local, a maioria propriedade dos moradores de Tatajuba, além das pousadas e casas com quartos de aluguel para turistas. Os donos das barracas contaram que trabalhar na lagoa não é fácil. No período das chuvas, sobe o volume da água e, conseqüentemente, precisam deslocar as barracas em direção das dunas, afastandose das águas (ver figuras 2 e 3 ).

A Regata Ecológica de Canoas de Tatajuba é o principal evento cultural, faz parte do calendário oficial de eventos do Município de Camocim. É organizado pelos moradores, intermediado pela associação. Mais do que um evento cultural e manifestação genuína, a regata é um momento de articulação política e demonstração social. Todos os anos as temáticas manifestam as preocupações, anseios e necessidades dos "povos do mar". Em 2004, a regata teve como tema: “Água é fonte de vida, confraterniza 10 anos”. Para a realização deste movimento, os moradores recebem apoio e patrocínio das instituições e pessoas que colaboram para a confecção do chamado pano da canoa. Dessa forma, cada canoa representa o seu patrocinador. Em 2004, a canoa vencedora foi patrocinada pelos alemães que faziam parte do projeto Pro-Renda em Tatajuba, sendo eles os responsáveis pela construção do site da comunidade ${ }^{9}$.

\footnotetext{
${ }^{9}$ Site de Tatajuba: <http:www.geocities.com/novatatajuba $>$.
} 
A Associação Comunitária dos Moradores de Tatajuba - ACOMOTA iniciou o planejamento do turismo comunitário, a partir de julho de 2002, com a realização de um Seminário de Planejamento, por meio do Instituto Terramar. A esse evento fizeram-se presentes convidados de outras comunidades como: Batoque - Aquiraz, Balbino - Cascavel, Caetanos - Sabiaguaba e Prainha do Canto Verde - Beberibe, além de participantes do Instituto Terramar, Comissão Pastoral da Pesca - CPP e representante de universidades. Foram discutidas estratégias e ações para o desenvolvimento do turismo, a criação de parcerias com outras instituições governamentais e não-governamentais, a troca de experiências entre as comunidades, a inserção de Tatajuba na Rede do Turismo Comunitário, além de um breve inventário sobre os atrativos de Tatajuba (TERRAMAR, 2002).

O turismo comunitário é desenvolvido pela ACOMOTA, com apoio de ONGs, pois as outras representações comunitárias seguem caminhos divergentes. Para tanto, foi criado o Regimento Interno do Grupo de Turismo Comunitário Sustentável de Tatajuba, em 2004. A observação desse documento demonstrou que a comunidade conduz seu processo permeado pelos padrões do capital, mas diferencia-se no ritmo, na infra-estrutura e nos beneficiados, buscando uma distribuição mais justa da renda entre os membros.

Nas coletas de depoimentos (PESQUISA DE CAMPO, 2004, 2005, 2006) realizadas, nas conversas e diálogos com os moradores de Tatajuba, foi possível captar algumas frases que, para a comunidade expressa o significado do turismo e de turista, e que, no meio das conversas, acabavam confundindo as duas expressões. Disseram que "o turismo é esse que chega. Porque tem turismo de várias coisas. Tem aquele que vem pra gastar e aquele que só vem pra sujar". Outro morador, disse que "o turista é aquele que vem para conhecer as comunidades. Os turistas ficam encantados com a comunidade, conversam com a população, muitos conhecem o povo da associação”. Um pescador complementou, dizendo que os turistas "são as pessoas que vêm de fora pra visitar e conhecer a localidade e seis pontos turísticos".

Uma moradora compreende que, para receber turistas, é necessária infra-estrutura, dizendo que os turistas são "pessoas passando férias, finais de semana, conhecendo os lugares e procurando conforto”. Ao questionar os moradores sobre o trabalho na atividade turística, declararam parte de suas dificuldades e anseios, fato que se confirma no depoimento de uma moradora (2004), ao dizer que "a gente tem vontade de trabalhar com o turismo, mas aí vem a 
parte financeira. As pessoas ainda não têm uma infra-estrutura necessária, mesmo o mínimo para o turista".

Sobre o turismo comunitário, o definem como: "é aquele que a gente procura desenvolver junto com as outras atividades, porque às vezes as comunidades deixam de trabalhar com as outras atividades e querem trabalhar só com o turismo” (Líder de Tatajuba, 28 anos, PESQUISA DE CAMPO, 2006). A declaração revela o desejo de trabalhar com o turismo, ao tempo que, demonstra o medo da gradativa decadência da pesca, como nas comunidades vizinhas, a exemplo de Jericoacoara, onde o turismo cresceu sem limite, em oposição às atividades tradicionais dos nativos, conforme constatado nos textos anteriores. Noutro depoimento, é revelada a idéia de que, nas comunidades, o turismo deveria ser realizado em pequenas proporções e gestado pelos residentes. Disse o morador que "a forma como tem sido feito é um caminho. Se construir grandes hotéis, Tatajuba vai perder o que as pessoas (turistas) gostam, a tranqüilidade” (Pescador, 35 anos, PESQUISA DE CAMPO, 2006).

Projetar o desenvolvimento do turismo em Tatajuba pela gestão comunitária é uma ação política, na medida em que os moradores busquem atingir objetivos em grupo. Quando conseguirem organizar e alcançar a coesão da comunidade, será possível garantir a permanência no lugar, o respeito pela cultura local e pelos meios de sobrevivência. Nesse sentido, configurar-se-á uma ação política desenvolvida no mundo do capital. É importante compreender, que o desenvolvimento do turismo pelas comunidades é resultante, ainda, da pressão do mercado sobre os moradores, que os induzem à criação de propostas de trabalho que se inserem na economia, isto é, a pesca e a agricultura que mantinham a sobrevivência das comunidades são ditas como atividades em "decadência", fato que é tomado como justificativa para ampliação de atividades que claramente fazem parte do universo do trabalho-mercadoria.

\section{Considerações Finais}

Tatajuba faz interface com o turismo de Jeri, dando-lhe relevo. Apesar das dificuldades de acesso à comunidade de Tatajuba, esta vem sendo apropriada pelo capital. A expropriação das terras dos pescadores se intensifica, a urbanização e modernização se aceleram, motivadas pelo turismo. Reproduzem-se as relações capitalistas, atropelando ou desfazendo as 
comunitárias. Ainda existem, entretanto, indícios de solidariedade entre os nativos, reveladas em suas práticas cotidianas, caracterizando a cultura dos "povos do mar", repleta de sentidos e representações sociais, diferenciadas das citadinas, pois se relacionam com uso direto da natureza, especialmente por sua intimidade com o mar.

As dificuldades provocadas pela diminuição dos meios de subsistência, a ausência de incentivos à pesca artesanal, à coleta e à agricultura familiar, causaram desordem nas práticas cotidianas da comunidade, que se encontra em um dilema perante essa transformação de usos, costumes e trabalhos. Com a decadência da pesca artesanal e da agricultura de subsistência, o "nativo" se torna submisso à produção de outrem, pelo trabalho-mercadoria, isto é, pelo assalariamento por atividades econômicas implantadas no litoral, como o turismo. E, assim, no litoral, as atividades modernas sobrepõem às tradicionais, mas estas não se extinguiram.

O lazer mercadoria tornou-se um negócio lucrativo para as empresas que buscam sempre novos lugares para esta prática, especialmente no litoral cearense. O espaço turístico Jericoacoara já aponta sinais de saturação, sendo Tatajuba um produto que deverá ser "desenvolvido" e "explorado", para complementar e inovar Jeri. Assim, Tatajuba, de espaço de reserva, torna-se um espaço do turismo. A lógica capitalista dos grandes pólos receptores turísticos é ali reproduzida.

A produção do espaço volta-se para empreendimentos externos, e, embora ainda não tenha descaracterizado a paisagem local, incitou a divisão interna da comunidade, o que é mais grave. O município de Camocim está sendo considerado área prioritária para os investimentos turísticos, sendo o Estado o principal mediador na atração de investidores e empreendimentos. Este litoral pouco visitado passou a integrar roteiros regionalizados (política de regionalização), para atender esta nova diretriz da reprodução capitalista.

Tatajuba é um território em conflito, exemplo da interface entre o turismo global e a tentativa de construção do turismo comunitário. A comunidade que tem o sentido de lugar, de referência, de coesão está ameaçada pelas atividades que ali se implantam. A perda dessa representação causa uma profunda desordem, a desestruturação de modos de vida e a insegurança nos residentes. $O$ conflito que se apresenta pela desarticulação entre os moradores, por um lado, ocasionou a divisão interna, por outro, despertou na comunidade o sentido da luta, da descoberta de possibilidades, sendo o turismo comunitário tecido nessa perspectiva. 


\section{Referências}

ACOMOTA. 2004. Regimento Interno do Grupo de Turismo Comunitário Sustentável de Tatajuba. Associação Comunitária dos Moradores de Tatajuba - ACOMOTA. Tatajuba - Camocim/CE: ACOMOTA, 6p.

BENI, M. C. s/d. Turismo Políticas Públicas e Desenvolvimento Regional e Urbano. Disponível em: $<$ http:www.etur.com.br/conteudocompleto $>$. Acesso em: 12/11/2005.

COMISSÃO DE DIREITOS HUMANOS E CIDADANIA DO CEARÁ. 2001. Ata da Audiência Pública em Camocim-CE: Implantação do Projeto Turístico em Tatajuba. Camocim-CE: 12 de setembro de 2001. 63 p. (Divisão do Serviço de Taquigrafia, Revisão e Anais).

FRANÇA, L. R. P. 2006. O Desenvolvimento do Turismo em Camocim e Tatajuba. Entrevista concedida a E. G. M. em março de 2006.

GIRÃO, R. 1971. Pequena História do Ceará. 3. ed. Vol. 5. Fortaleza: Imprensa Universitária. (Biblioteca de Cultura. Revista Série A - Documentário).

GOVERNO DO ESTADO DO CEARÁ - SECRETARIA DO TURISMO DO ESTADO DO CEARÁ - SETUR.2003a. PDTIS - Plano de Desenvolvimento Integrado do Turismo e Sustentável do Pólo Costa do Sol. Avaliação do PRODETUR-CE I. Ruschmann Consultoria. Fortaleza: SETUR, 114p. . IPECE - Instituto de Pesquisa e Estratégia Econômica do Ceará. SECRETARIA DO PLANEJAMENTO E COORDENAÇÃO (SEPLAN). 2000-2003. Perfil Básico dos Municípios. Fortaleza: IPECE, 10p. Disponível em: <http:www.ipece.ce.gov.br>. Acesso em: 25/10/2006.

HaGUeTte, T. M. F. 1987. Metodologias Qualitativas na Sociologia. Petrópolis: Rio de Janeiro: Editora Vozes, 163p.

IBAMA. MINISTÉRIO DO MEIO AMBIENTE. 2001. Instituto Brasileiro do Meio Ambiente e dos Recursos Naturais Renováveis - IBAMA. Laudo Ambiental da Localidade de Tatajuba Camocim/CE. Fortaleza: IBAMA, Gerência Executiva do IBAMA -CE. 55p.

IBGE. INSTITUTO BRASILEIRO DE GEOGRAFIA. 2000. Censo Demográfico. IBGE, p.17.

MALDONADO, S. C. 1993. Mestres e Mares: espaço e indivisão na pesca marítima. 2. ed. São Paulo: Annablume. 194p. (Selo Universidade, 7a. Coleção Antropologia).

MENDES, E. G; CORIOLANO, L. N. M. T. 2003. A Prainha do Canto Verde: locus de resistência e Turismo Comunitário. In: CORIOLANO, L. N. M. T; LIMA, L. C. Turismo Comunitário e Responsabilidade Socioambiental. Fortaleza: EDUECE, 2003. p.173 -196. 
2006. De Espaço Comunitário a Espaço do Turismo: conflitos e resistências em Tatajuba, Camocim-CE. Fortaleza. 192f. Dissertação (Mestrado Acadêmico em Geografia). Universidade Estadual do Ceará, 2004.

NETTUR - LABORATÓRIO DE ESTUDOS DO TERRITÓRIO E TURISMO. 2006. Universidade Estadual do Ceará-UECE. A (Re)estruturação do Litoral Cearense pelos Serviços da Atividade Turística a partir da década de 1990. (Projeto de pesquisa). Fortaleza: NETTUR,/UECE.

PESQUISA DE CAMPO. 2004; 2005; 2006. Entrevistas e coletas de depoimentos concedidas pelos moradores, pescadores e lideranças da Comunidade de Tatajuba, Camocim-CE a E. G. M., realizadas em ago. e nov. (2004), fev. (2005) e jan. (2006).

POEMA TATAJUBA. 2001. Disponível em: <http:www.geocities.com/novatatajuba>. Acesso em: 6 de abril de 2005.

SANTOS, J. L. D. 1983. O que é Cultura? São Paulo: Ed. Brasiliense. 87p.

SANTOS, M. 2004. Pensando o Espaço do Homem. São Paulo: EDUSP, 90p. .2005. Da Totalidade ao Lugar. São Paulo: EDUSP, 176p.

SEABRA, G. de F. 2001. Pesquisa Científica: o método em questão. Brasília: Editora UNB, 124p.

TATAJUBA. s/d. Disponível em: <http:www.geocities.com/novatatajuba $>$. Acesso em: 6 de abril de 2005.

TERRAMAR. 2002. Relatório do Seminário de Planejamento do Turismo Comunitário de Tatajuba Camocim/CE. Fortaleza: Instituto Terramar, 50p.

\section{Recebido em: 05/01/2007}

Aprovado em: 18/01/2007 